\title{
Comunicativo ou pedagógico? O uso do WhatsApp como ferramenta híbrida em uma disciplina de graduação
}

\author{
Communicative or pedagogical? The use of WhatsApp as a hybrid tool in \\ a graduation discipline
}

\author{
Comunicativo o pedagógico? El uso de WhatsApp como herramienta hibrida em \\ una disciplina de graduacion
}

Marcus Henrique Linhares Ponte Filho ${ }^{1}$ Eunice Andrade de Oliveira Menezes ${ }^{2}$

\begin{abstract}
Resumo: $O$ estudo é fruto de uma experiência de utilização do aplicativo WhatsApp como ferramenta de suporte comunicativo em uma disciplina no curso de Pedagogia de uma universidade pública. O WhatsApp foi escolhido para servir como suporte comunicativo entre professores e alunos da disciplina, mas a utilização que os estudantes fizeram do aplicativo ultrapassou a proposta inicial, fazendo o uso do aplicativo passar de uma ferramenta comunicativa para um suporte pedagógico dos discentes. Uma análise do discurso discente foi realizada por meio da utilização do WhatsApp na disciplina a partir dos pressupostos teóricos da Educomunicação, campo de pesquisa que defende a ideia de que o uso de recursos tecnológicos em processos educativos deve ser feito de forma democrática, dialogada e participativa. Pôde-se perceber que o WhatsApp ampliou a comunicação entre os sujeitos, embora essa comunicação nem sempre tenha se dado de forma alteritária. Dessa forma, o uso do aplicativo na disciplina em questão demonstrou que, apesar de gozar de popularidade entre os estudantes, o WhatsApp nem sempre foi capaz de formar um ecossistema comunicativo, uma vez que a comunicação mantida entre professores, monitores e alunos não parecia estar aberta aos interesses do interlocutor.
\end{abstract}

Palavras-chave: Informática Educativa. Ensino Híbrido. WhatsApp. Comunicação

Abstract: The study is the result of an experience of using the WhatsApp application as a communicative support tool in a discipline in the Pedagogy course of a public university. WhatsApp was chosen to serve as communicative support between teachers and students of the discipline, but the use that students made of the application went beyond the initial proposal, making the use of the application move from a communicative tool to a pedagogical support for students. An analysis of the student discourse was performed using WhatsApp in the discipline based on the theoretical assumptions of Educommunication, a research field that defends the idea that the use of technological resources in educational processes should be done in a democratic, dialogued and participatory way. It could be seen that WhatsApp has expanded communication between subjects, although this communication has not always occurred in an alteritarian way. Thus, the use of the application in the discipline in question demonstrated that, despite enjoying popularity among students, WhatsApp was not always able to form a communicative ecosystem, since the communication maintained between teachers, monitors and students did not seem to be open to the interests of the interlocutor.

Keywords: Educational Informatics. Hybrid teaching. WhatsApp. Comunication.

1 Doutor em Educação, Professor Adjunto da Universidade Federal do Cariri (UFCA).

2 Doutora em Educação, Professora da Universidade Federal do Cariri (UFCA). 
Resumen: El estudio es el resultado de una experiencia de uso de la aplicación WhatsApp como herramienta de apoyo comunicativo en una disciplina del curso de Pedagogía de una universidad pública. WhatsApp fue elegido para servir como soporte comunicativo entre docentes y alumnos de la disciplina, pero el uso que los estudiantes hicieron de la aplicación fue más allá de la propuesta inicial, haciendo que el uso de la aplicación pasara de una herramienta comunicativa a un soporte pedagógico para los estudiantes. Se realizó un análisis del discurso del estudiante mediante WhatsApp en la disciplina a partir de los supuestos teóricos de la Educomunicación, campo de investigación que defiende la idea de que el uso de los recursos tecnológicos en los procesos educativos debe realizarse de forma democrática, dialogada y participativa. Se pudo observar que WhatsApp ha ampliado la comunicación entre sujetos, aunque esta comunicación no siempre se ha dado de forma alteritaria. Así, el uso de la aplicación en la disciplina en cuestión demostró que, a pesar de gozar de popularidad entre los estudiantes, WhatsApp no siempre fue capaz de formar un ecosistema comunicativo, ya que la comunicación que se mantenía entre profesores, monitores y alumnos no parecía ser abierto a los intereses del interlocutor.

Palabras-chave: Informatica Educativa. Enseñanza Híbrida. WhatsApp. Comunicación.

\section{INTRODUCCIÓN}

O uso das redes sociais como ferramentas de suporte pedagógico é uma realidade cada vez mais comum no século XXI, haja vista que ambientes como Facebook e Twitter têm despertado o interesse de educadores, em função da popularidade que gozam entre seus usuários, bem como da capacidade de interação que promovem entre educadores e discentes.

De acordo com Lopes (2011), o uso de redes sociais em práticas pedagógicas contribui para um caráter absolutamente transdisciplinar às atividades que envolvem tais ambientes, tanto do ponto de vista comunicacional quanto do ponto de vista educativo, uma vez que exige dos profissionais envolvidos no processo educacional uma abertura às múltiplas capacidades exigidas pelas redes sociais, como por exemplo, sensibilidade no manuseio dessas mídias; alteridade no que diz respeito às habilidades e capacidade de comunicação dos sujeitos nesses espaços virtuais; compreensão do tipo de comunicação que é mantida nesses ambientes, dentre outras.

De certa maneira, a educação contemporânea possui (ou deveria possuir) um atributo típico da pós-modernidade: a capacidade de estimular a comunicabilidade dos alunos através da descentralização das atividades realizadas no processo de ensinoaprendizagem que por tradição, são focalizadas no professor. Essa descentralização pode envolver o uso de tecnologias da informação e da comunicação (TIC) ou outras mídias digitais (computador, televisão, celular, Internet etc.), ambientes virtuais de aprendizagem (Moodle, Teleduc, Solar etc.) ou, até mesmo, redes sociais populares entre os estudantes, como forma de oferecer a estes oportunidades de ultrapassar a sala de aula convencional como lócus de produção de conhecimento.

A utilização desses ambientes e de recursos diferenciados exige a ressignificação da ação docente, ao mesmo tempo em que também não rejeitam o paradigma pedagógico no qual os docentes estão inseridos. Assim, o objetivo de se utilizar ambientes alternativos de aprendizagem não é, de modo algum, duvidar de outras possibilidades de práticas pedagógicas (ainda que opostas à racionalidade técnica), mas sim mostrar aos docentes que esses espaços virtuais e as mídias digitais proporcionam uma maneira diferente de se ler, isto é, interpretar e acessar os conhecimentos abordados no processo de ensino-aprendizagem.

O uso pedagógico de redes sociais também tem se tornado parte importante do ensino híbrido, que busca combinar atividades presenciais e à distância através da oferta de experiências educacionais que superem a abordagem unilateral do conhecimento, tal como exposta no ambiente convencional da sala de aula.

Neste ensaio, apresentaremos os resultados da utilização do WhatsApp como 
ferramenta comunicativa em uma disciplina de graduação ofertada em modelo híbrido no curso de Pedagogia da Universidade Federal do Ceará, no semestre 2 do ano de 2019. Esperamos demonstrar que o uso feito pelas redes sociais em atividades pedagógicas nem sempre se limita à ideia inicial estabelecida pelos docentes, mas amplia-se à medida que os alunos encontram novas utilidades para a ferramenta, ampliando seu caráter comunicacional e fortalecendo a autonomia dos discentes.

A pesquisa caracteriza-se como um estudo de natureza qualitativa, analisando o discurso dos alunos da disciplina durante a utilização do WhatsApp, a partir da teoria discursiva de Maingueneau (2006). A escolha pela análise discursiva como estratégia de trabalho sobre os dados obtidos no estudo se deu pela abrangência desse método científico, uma vez que o discurso não se manifesta apenas de forma escrita ou oral, mas "é uma organização situada para além da frase" (MAINGUENEAU, 2006, p.95). A partir deste pressuposto, descreveremos situações ocorridas na disciplina através da utilização do aplicativo, analisando como esse uso ultrapassou as expectativas iniciais dos professores e de que forma essa utilização influenciou na qualidade da comunicação mantida entre docentes e discentes da disciplina, ao mesmo tempo em que apresentaremos de forma resumida alguns conceitos pedagógicos do ensino híbrido, modalidade educacional que orientou a oferta da disciplina na qual utilizamos o WhatsApp.

\section{REFERENCIAL}

\subsection{O ENSINO HÍBRIDO E OS MITOS SOBRE A} UTILIZAÇÃO DE TECNOLOGIAS NA EDUCAÇÃO

A utilização das tecnologias da informação e da comunicação no contexto educacional ainda enfrenta certos dilemas de aceitação por parte de professores e gestores, seja pela falta de um método de ensino que seja considerado uma unanimidade entre os profissionais da educação, seja pela falta de formação específica para utilização de recursos tecnológicos em sala de aula (RODRIGUES, 2016). E é nesse contexto de superação de desconfianças, que o ensino híbrido propõe novas formas de pensar o ato educacional com o uso de recursos tecnológicos.

Para Moran (2002), o modelo híbrido de educação propõe atividades de ensino descentralizadas, retirando da figura do professor a exclusividade no que diz respeito à abordagem do conhecimento. Essa proposta descentralizadora de educação procura estimular a própria criticidade dos alunos sobre o que estão estudando e sobre o conhecimento que está sendo produzido. Assim, o uso de ambientes virtuais de aprendizagem, TIC, assim como as redes sociais utilizadas pelos estudantes em seu cotidiano, se fazem atrativos pela popularidade que gozam entre os alunos da educação contemporânea, uma vez que "[...] os meios eletrônicos falam a linguagem dos jovens e também o conteúdo desejado, que repercute no seu íntimo" (MORAN, 2002, p. 22).

Ante a esse panorama, pensar a educação na sociedade da informação e do conhecimento exige das políticas educacionais, das universidades (enquanto espaços formativos), e das escolas, formas de equacioná-la ao contexto globalizado de desenvolvimento tecnológico, de modo a conectar os programas curriculares dos cursos de formação de professores às possibilidades que as tecnologias digitais oferecem.

Segundo Diesel (2019), a noção de espaço formal educacional que as escolas difundem através do modelo tradicional de ensino já não encontra mais eco na busca livre de conhecimento empreendida pelos alunos contemporâneos: assim, cada vez mais os estudantes tendem a buscar saberes fora do ambiente formal escolar, ampliando o conceito de "espaços de aprendizagem" e abrindo caminho para novos modelos de ensino que possibilitem aos discentes maior autonomia, bem estar e prazer em sua aprendizagem, já que "o aluno deve sentir-se confortável e estimulado no habitat onde é realizado o processo de aprendizagem" (DIESEL et al, 2019, p. 379). 
Para Silva (2014), o ensino híbrido constituise numa modalidade de ensino capaz de misturar os melhores elementos do ensino presencial e da educação à distância: assim, busca-se incentivar o aluno a construir sua aprendizagem, abordando o conhecimento através do uso de recursos tecnológicos diversos (ambientes virtuais de aprendizagem, redes sociais, softwares), ao mesmo tempo em que se enriquecem as atividades presenciais dando aos alunos oportunidades de debater e analisar os conteúdos que produziram através da utilização dos diversos aparatos tecnológicos.

É necessário, contudo, ressaltar que a utilização de aparatos tecnológicos não é o objetivo final do ensino híbrido. Todas as tecnologias usadas nessa modalidade de ensino têm caráter unicamente mediador, buscando criar um sentimento de responsabilidade sobre a construção do conhecimento no aluno. Dessa forma, o ensino híbrido busca também evitar propagar uma utilização fria e mecânica dos aparatos tecnológicos, que infelizmente ainda se manifesta por meio de atividades centralizadoras e pouco comunicativas no ambiente escolar (KAPLUN, 2014).

É necessário que as instituições educacionais (universidades e escolas), e mormente as políticas educacionais, alcem esforços coletivos para superar o desafio democrático do acesso à informação e ao conhecimento via tecnologias digitais, como forma de garantir aos estudantes (em especial os da rede pública de ensino) as condições mínimas necessárias para o uso desses recursos. Mas, como alcançar tais metas?

Segundo Soares (2011), em se tratando de políticas públicas, cabe a estas prover às instituições não apenas as ferramentas tecnológicas propriamente ditas, mas um processo formativo que dê conta de qualificar os usuários (sobretudo, os professores) para seu uso devido, de forma que superem as chamadas capacitações técnicas, guiadas por uma racionalidade mecânica e fria que procura apresentar fórmulas miraculosas de utilização das tecnologias aos docentes.

Falar de ensino híbrido no Brasil é falar de superação de estigmas, haja vista que apesar dessa modalidade de ensino propor novas formas de se utilizar recursos tecnológicos, ainda há uma resistência em se mesclar o ensino presencial e atividades à distância através do uso de TIC. É desnecessário dizer que para que o ensino híbrido possa ser bem sucedido, as instituições formativas precisam estar abertas a esta inovação pedagógica, compreendendo que sua aplicação não equivale simplesmente a uma "modernização do ensino", mas que sua utilização só obterá êxito se for realizada de forma crítica e consciente pelos usuários, devendo, necessariamente, estar associada à realidade educativa da comunidade escolar.

Rodrigues (2016) enfatiza que o ensino híbrido é também conhecido no Brasil como "ensino semipresencial" e sempre pressupõe a utilização de algum recurso tecnológico (escolhido a partir dos objetivos do professor nas atividades que irá realizar), combinando "estudos no espaço escolar e fora dele, ao utilizar a tecnologia como ferramenta essencial nesse processo" (RODRIGUES, 2016, p. 21). Fica evidente a importância que as tecnologias digitais e os ambientes virtuais de aprendizagem possuem nesta proposta de ensino; porém, mesmo tendo um potencial pedagógico a ser considerado, e ainda que estejam em ampla expansão no que tange à sua utilização para fins educativos, torna-se perceptível também que alguns ambientes virtuais (como as redes sociais) ainda parecem despertar certo temor entre os profissionais da educação, principalmente, no que diz respeito à delimitação do espaço-aula. Mcluhan (2007) afirma que esse temor em relação ao poder das tecnologias existe em todas as esferas sociais, mas é na educação que ele parece ganhar ares quase sombrios: o ambiente educacional formal tem receio de usar as tecnologias e as redes sociais justamente pelo fascínio que essas exercem sobre os alunos, esse fascínio gera entre professores e gestores, o receio da "perda de controle" sobre os alunos, o que, por sua vez, poderia desencadear um colapso na prática educativa.

Este fenômeno descrito pelo pesquisador canadense Marshall Mcluhan também é confirmado por Wajnsztejn et al (2020), 
que ressalta o fato de que a velocidade das transformações no campo educacional não acompanhou a velocidade das transformações que a comunicação sofreu na sociedade pósmoderna. A autora enfatiza que essa lentidão nas mudanças necessárias na educação se caracteriza como um fenômeno contraditório, "uma vez que o acesso à informação impacta diretamente nas práticas pedagógicas" (WAJNSZTEJN et al, 2020, p. 25).

Tal receio dos profissionais da educação em usar certas TIC (como as redes sociais) em suas atividades docentes parece crescer ainda mais, em virtude da própria natureza desses meios de comunicação: essas tecnologias são ferramentas autônomas, não atreladas ao modelo pedagógico escolar, que gozam de popularidade junto ao público infanto-juvenil e possuem uma imagem quase que totalmente relacionada ao entretenimento e à informação descompromissada. Mcluhan (2007) os trata como extensões do próprio ser humano, uma vez que esses meios oferecem aquilo que o homem busca (informação, entretenimento, prazer), sendo, por isso, considerados por seus críticos como "produtores de conhecimento, mas não produtores de consciência" (MCLUHAN, 2007, p. 67).

Há, contudo, grande diferença entre produzir conhecimento e produzir níveis de consciência (sobretudo, reflexivos). E entendemos que isso não se ancora meramente no uso e domínio das tecnologias discutidas, mas sim numa abordagem pedagógica sustentada em princípios comunicativos e democráticos, em que os sujeitos possam refletir sobre os recursos tecnológicos dos quais fazem uso, manifestando suas reflexões de forma coletiva e descentralizada (KAPLUN, 2012). Assim, ainda que a produção do conhecimento seja atividade que opera, inegavelmente, na transformação das pessoas, é mister, convenhamos, que não se considere o conhecimento, por si só, como elemento propulsor de mentes conscientizadas.

Nesse caso, temos aqui um pequeno dilema de cariz sociológico: se por um lado as redes sociais (como o WhatsApp) são populares e têm um potencial pedagógico e comunicativo a ser explorado, por outro lado o uso dessas redes em atividades formais educacionais (como a experiência realizada em nossa disciplina) nem sempre se limita aos objetivos propostos inicialmente; ao contrário: o uso que é feito dessas redes é adaptado, incrementado e ampliado por parte de seus usuários, gerando novas formas de comunicação, muitas vezes, não previstas inicialmente no planejamento pedagógico dos professores, seja pela natureza de cada rede social utilizada, seja pelas características específicas que elas possuem, e principalmente pela racionalidade e intencionalidade que motivam seu uso por parte de alunos e professores.

Ainda assim, não nos parece razoável criticar o uso pedagógico de redes sociais, seja no ensino presencial, no ensino à distância ou no ensino híbrido; devemos sim, compreender esse uso a partir das características específicas que essas redes possuem, analisando seus potenciais pedagógicos e as dificuldades relacionadas à sua utilização.

\section{PROCEDIMENTOS METODOLÓGICOS}

\subsection{A ANÁLISE DISCURSIVA COMO ESTRATÉGIA DE TRABALHO SOBRE OS DADOS DO ESTUDO}

Os dados obtidos neste estudo foram analisados a partir da teoria discursiva de Dominique Maingueneau, linguista que defende a ideia de que os discursos são acima de tudo manifestações sociais das convicções dos sujeitos que os manifestam (MAINGUENEAU, 2006). Para isso, descrevemos de forma ampla situações que foram vivenciadas durante a realização da disciplina ministrada durante o 20 semestre de 2019, quando o aplicativo WhatsApp foi utilizado como suporte comunicativo da disciplina. Dessa forma, todas as descrições feitas da postura dos estudantes durante a utilização do aplicativo tem o objetivo de analisar primordialmente suas próprias motivações e o discurso manifestado em suas ações, superando a mera análise de declarações feitas pelos discentes, já que "[...] a própria atividade verbal encontra- 
se relacionada com atividades não-verbais" (MAINGUENEAU, 2006, p. 96).

A análise discursiva do uso do WhatsApp proposta neste estudo é realizada a partir dos pressupostos da Educomunicação, campo de pesquisa que defende a ideia de que a qualidade da comunicação mantida entre sujeitos envolvidos em processos educacionais é mais importante que a própria utilização de recursos tecnológicos nesses processos (SOARES, 2011). Assim, o uso feito do aplicativo nesta pesquisa interessa-nos, acima de tudo, pela qualidade da comunicação que foi mantida entre professores e estudantes durante esta utilização.

\subsection{A DISCIPLINA DE INFORMÁTICA EDUCATIVA E A DECISÃO DE SE USAR O WHATSAPP COMO FERRAMENTA COMUNICATIVA}

A disciplina na qual utilizamos o WhatsApp intitulava-se Informática Educativa e trata-se de um componente optativo pertencente à matriz curricular do curso de Licenciatura em Pedagogia da Universidade Federal do Ceará UFC. A disciplina é oferecida semestralmente na Faculdade de Educação - FACED da UFC, tanto aos alunos do curso de Pedagogia quanto a alunos de outras licenciaturas (como um componente optativo-livre).

Tal disciplina é um componente curricular pertencente ao Departamento de Estudos Especializados (DEE) da FACED/UFC, possui carga horária de 64 horas/aula (4 créditos), sendo ministrada prioritariamente pelos professores do Laboratório Multimeios (grupo de pesquisas coordenado pelo Prof. Hermínio Borges Neto, que trabalha diretamente com investigações ligadas aos campos de Mídias e Educação, Educomunicação, Informática Educativa e Tecnologias Educacionais).

No que diz respeito à sua metodologia de aplicação, a disciplina de Informática Educativa é oferecida no modelo híbrido (semipresencial), combinando atividades presenciais, previamente agendadas, e atividades à distância em ambientes virtuais e redes sociais escolhidas pelos professores do Laboratório Multimeios.

O principal ambiente virtual de ensino utilizado na disciplina é a plataforma Moodle Multimeios, espaço virtual acessado pelos estudantes matriculados na disciplina Informática Educativa. Nesse ambiente, os alunos podem visualizar os textos trabalhados na disciplina, participar de fóruns de discussão, sessões de bate-papo (chat) agendadas pelos professores, e assistir vídeos hospedados dentro da plataforma.

No que tange às redes sociais, o principal recurso comumente utilizado na disciplina de Informática Educativa é o Facebook, espaço onde os alunos participam de fóruns de apresentação e podem postar trabalhos solicitados em formato de vídeo. Todavia, no semestre 2 do ano de 2019, além do Facebook, decidimos usar o WhatsApp como rede social na disciplina em questão, em virtude de fatores excepcionais que favoreceram a escolha do aplicativo como suporte comunicacional. Esses fatores foram basicamente dois: a quantidade de alunos matriculados na disciplina, e a maior popularidade (em matéria de utilização) do WhatsApp em relação ao Facebook (ALVES, 2019).

No semestre 2 do ano de 2019, foram ofertadas 4 turmas de Informática Educativa no curso de Pedagogia da Faculdade de Educação da Universidade Federal do Ceará. Com isso, 115 alunos se matricularam na disciplina, gerando uma série de contratempos aos professores do Laboratório Multimeios, responsáveis por ministrarem o componente curricular.

Como nem todos os alunos matriculados em Informática Educativa no 20 semestre do ano de 2019 possuíam Facebook (rede social utilizada semestralmente na disciplina), e como o número total de estudantes estava bastante elevado, chegamos à conclusão de que deveríamos escolher outra rede social, além do Facebook, que não funcionasse só como ambiente de apresentação dos alunos (ou como repositório de trabalhos da disciplina). Essa rede social deveria ser utilizada pela maior quantidade possível de alunos, 
e permitir contato com a turma de maneira rápida e acessível, de forma a propiciar maior agilidade na comunicação entre docentes e discentes (acelerando a divulgação de avisos relacionados à Informática Educativa). Assim, em um breve levantamento que fizemos antes do início da disciplina, chegamos à conclusão de que a principal rede social a ser utilizada naquele momento deveria ser o WhatsApp (conforme comprovado no quadro abaixo):

Quadro 1 - Comparativo entre o uso do WhatsApp e o uso do Facebook na disciplina de Informática Educativa do curso de Pedagogia da UFC, no 2o semestre de 2019

\begin{tabular}{|ccc|}
\hline $\begin{array}{c}\text { Quantidade de usuários da rede } \\
\text { social matriculados na disciplina }\end{array}$ & WhatsApp & Facebook \\
\hline $\begin{array}{c}\text { Principal função da rede social na } \\
\text { disciplina }\end{array}$ & $\begin{array}{c}\text { Facilitar a comunicação com os } \\
\text { estudantes. }\end{array}$ & $\begin{array}{c}\text { Possibilitar a apresentação dos } \\
\text { estudantes na disciplina e a } \\
\text { entrega de atividades agendadas. }\end{array}$ \\
\hline $\begin{array}{c}\text { Facilidades disponibilizadas pela } \\
\text { rede social }\end{array}$ & $\begin{array}{c}\text { Compartilhamento de arquivos da } \\
\text { disciplina; comunicação quase } \\
\text { instantânea entre professores e } \\
\text { estudantes; ritmo intenso de } \\
\text { interação por parte dos discentes. }\end{array}$ & $\begin{array}{c}\text { Compartilhamento de arquivos da } \\
\text { disciplina; possibilidade de entrega } \\
\text { de atividades agendadas. }\end{array}$ \\
\hline
\end{tabular}

\section{RESULTADOS E DISCUSSÃO}

\subsection{O USO DO APLICATIVO PELOS ALUNOS DE INFORMÁTICA EDUCATIVA}

Inicialmente, a escolha do aplicativo WhatsApp como rede social da Informática Educativa no 20 semestre de 2019 se deu com um único objetivo: facilitar a comunicação com os cento e quinze estudantes matriculados na disciplina (tarefa que sabíamos ser difícil com o uso de qualquer ferramenta tecnológica, diante do elevado número de alunos matriculados). 0 Facebook continuaria sendo utilizado com as mesmas funcionalidades do semestre anterior (fórum de apresentação dos alunos e entrega de vídeos), e o principal ambiente virtual de ensino de Informática Educativa continuaria sendo a plataforma Moodle Multimeios.

Foi então criado um grupo oficial de Informática Educativa no WhatsApp, de forma que todos os estudantes matriculados fossem incluídos no ambiente, assim como os professores e monitores da disciplina. Em teoria, todas as atividades que seriam realizadas na disciplina já estavam definidas; na prática, porém, a utilização que os alunos fizeram do WhatsApp superou completamente as expectativas do planejamento pedagógico que havia sido feito: de suporte de comunicação, o aplicativo tornou-se ferramenta pedagógica propriamente dita, fazendo com que alguns alunos optassem por manter contato com seus colegas de turma através do próprio WhatsApp (e não através do ambiente Moodle, principal ambiente virtual utilizado na Informática Educativa).

A plataforma Moodle Multimeios possuía todas as informações essenciais da Informática Educativa, como o cronograma da disciplina (com datas de avaliações e entregas de trabalhos), os critérios de avaliação, os textos trabalhados (a disciplina não aborda textos impressos, e sim em formato digitalizado), e a lista final de notas com o resultado do semestre letivo. Consideramos o Moodle Multimeios como um típico ambiente educomunicativo, que permite ao aluno pesquisar todas as informações que julgue necessárias à construção de seu aprendizado, dando-Ihe autonomia para direcionar sua abordagem aos conteúdos da disciplina e reconstruindo seu saber a partir de suas próprias análises, características que Soares (2011) classifica como típicas de um ecossistema comunicativo.

Por outro lado, o WhatsApp tinha algo que parecia ser muito atraente aos alunos: a praticidade. Se comparado ao ambiente Moodle, o WhatsApp não exigia acessar nenhum site, ou fazer nenhum log in, todos 
os estudantes já estavam conectados ao aplicativo em tempo quase integral através de seus próprios aparelhos celulares. Isso fez com que, em certo momento do semestre letivo, verificássemos que a interação dos alunos estava bem mais intensa no aplicativo que na plataforma Moodle Multimeios, confirmando o fato de que o uso pedagógico de redes sociais (como WhatsApp e Facebook) tende a gozar de popularidade entre os discentes justamente por facilitar a comunicação e a interação que mantém nas disciplinas que utilizam essas ferramentas (SILVA, 2014).

Essa "subversão" dos alunos à ordem de prioridades virtuais proposta por nós, docentes do Laboratório Multimeios que ministramos a disciplina de Informática Educativa no semestre 2019.2, de certa forma nos assustou: não era aquela a proposta que pensávamos inicialmente para a condução das atividades da disciplina. A partir dali o trabalho dos monitores intensificou-se, de forma a tentar informar os estudantes que sua participação primordial deveria se dar no ambiente Moodle Multimeios, deixando o WhatsApp apenas para informações urgentes ou lembretes. Ainda assim, era comum percebermos no grupo de Informática Educativa no WhatsApp, mensagens de estudantes pedindo que outros colegas de turma compartilhassem através do aplicativo os textos trabalhados na disciplina; ou alunos perguntando se poderiam entregar seus trabalhos escritos através do próprio aplicativo (e não através do Moodle).

De certa forma, a inversão de prioridades feitas pelos alunos (preferindo se comunicar através da rede social que escolhemos, ao invés do ambiente virtual principal da disciplina), nos confirma a ideia defendida por José Manuel Moran de que, em se tratando do uso de tecnologias na educação, são os alunos que ditam como será essa utilização (e não necessariamente os professores), pois esses recursos "[...] contam o dia-dia dos usuários" (MORAN, 2002, p. 22).

A utilização que promovemos do WhatsApp na disciplina de Informática Educativa, ainda que tivesse um objetivo puramente comunicativo, foi reorientada de acordo com as experiências prévias dos estudantes (já acostumados a usar o aplicativo). Uma autonomia expressada pelos estudantes de forma espontânea e até certo ponto não prevista por nós que fazíamos parte do corpo docente da disciplina, mas que se caracterizou, ainda assim, como expressão cultural dos alunos, e da forma de utilizar o aplicativo que havíamos escolhido como ferramenta comunicativa da disciplina.

\subsection{ALTERIDADE OU AUTORITARISMO? A COMUNICAÇÃO MANTIDA PELOS ESTUDANTES DE INFORMÁTICA EDUCATIVA ATRAVÉS DO APLICATIVO WHATSAPP}

Outro ponto que merece nossa atenção, neste artigo, é o tipo de comunicação que era comumente mantido pelos estudantes no grupo da disciplina no WhatsApp. Aqui, damos atenção para a qualidade da comunicação que foi preservada através da utilização do aplicativo, por parte dos sujeitos envolvidos no processo educativo, partindo da ideia de que toda comunicação mantida em processos educacionais precisa ser construída em um ambiente comunicativo saudável, já que educar é necessariamente comunicar algo, e não se educa com qualidade quando não se comunica com qualidade (SOARES, 2011).

Por ter uma utilização extremamente prática, e por ter se tornado rapidamente a principal ferramenta utilizada pelos estudantes (superando até mesmo o principal ambiente virtual da disciplina), o uso do WhatsApp por parte dos alunos passou a ocorrer de maneira frenética, mesmo com o anúncio feito por parte da equipe docente da disciplina, de que os atendimentos através do aplicativo seriam realizados em horários pré-estabelecidos, de acordo com a disponibilidade de professores e monitores. Como rede social, o grupo oficial da disciplina no aplicativo passou a ser ocupado rapidamente por conversas nem sempre relacionadas aos conteúdos de Informática Educativa, mas também por informes variados dos alunos, notícias gerais (sem ligação com o tema da disciplina), ou mesmo diálogos livres que em nenhum momento foram proibidos, já que a comunicação mantida entre os 
estudantes não podia ser repreendida (fato que se comprovaria absolutamente contrário aos pressupostos da Educomunicação).

O pesquisador canadense Marshall Mcluhan afirma que os meios de comunicação agem diretamente sobre as formas de nos comunicar, já que "por serem extensões de nossos sentidos, estabelecem novos índices relacionais" (MCLUHAN, 2007, p. 72). Nesse caso, podemos nos questionar: até que ponto a praticidade propiciada pelo manuseio do WhatsApp aos alunos de Informática Educativa no 2ㅇ semestre do ano de 2019 na Faculdade de Educação da UFC, não tornou sua comunicação um pouco mais centrada em si, e menos focada nos propósitos da disciplina?

Os alunos já tinham ampla experiência com o uso de WhatsApp; porém, não sabemos até que ponto manejavam o aplicativo (mesmo dentro do grupo oficial da disciplina) apenas em atividades acadêmicas, ou se esse uso incluía comunicações não atreladas aos conteúdos de Informática Educativa. Nosso objetivo primordial era proporcionarmos um ambiente de rápida comunicação com os estudantes, usando o WhatsApp unicamente para dar informes rápidos e tirar dúvidas dos alunos a respeito de questões ligadas à disciplina. Porém, conforme já afirmamos anteriormente, o uso que os discentes fizeram do aplicativo foi reorientado para seus próprios objetivos, a partir de suas próprias experiências prévias de utilização do aplicativo, fazendo com que nós, professores de Informática Educativa, tivéssemos que reorganizar o planejamento inicial da disciplina, de forma a nos adaptar ao novo uso que os alunos estavam fazendo da rede social.

Com a extensa quantidade de estudantes matriculados na disciplina, e a frequência com que passaram a se comunicar pelo grupo oficial no WhatsApp, estabelecemos um horário virtual de atendimento às dúvidas dos discentes, procurando organizar a abordagem feita por eles aos professores e monitores da disciplina. Nesse sentido, foi elaborado um cronograma semanal de atendimento virtual, onde monitores e professores de Informática Educativa responderiam dúvidas e dariam informações relacionadas à disciplina aos alunos. Todavia, esses horários não foram seguidos pelos estudantes; ao contrário: com a intensificação da utilização do WhatsApp, era comum recebermos mensagens dos alunos, fora dos horários estabelecidos para atendimento virtual.

Com o decorrer do semestre letivo, as reuniões de planejamento de Informática Educativa tornaram-se cada vez mais intensas, e os monitores da disciplina passaram a relatar mensagens dos estudantes no WhatsApp até mesmo no período da madrugada. Mais que isso: muitas dúvidas relatadas pelos alunos poderiam ter sido sanadas com uma consulta à plataforma Moodle Multimeios, principal ambiente virtual da disciplina (mas que estava sendo superado pela popularidade e praticidade do WhatsApp).

Segundo Martin-Barbero (2014), os processos comunicativos estabelecidos no campo educacional só são exercidos com qualidade quando se estabelecem os chamados "ecossistemas comunicativos". Para o pesquisador colombiano, os ecossistemas comunicativos são ambientes em que as comunicações mantidas entre os sujeitos são feitas de forma democrática, autônoma, descentralizada e pautadas no respeito ao próximo. Dessa forma, as comunicações que se dão em ambientes com essas características, são "alteritárias" (preocupadas com o próximo) e não "autoritárias".

Tais premissas nos remetem a uma indagação: até que ponto as comunicações mantidas no 2 o semestre letivo do ano de 2019 no grupo oficial de Informática Educativa no WhatsApp foram realmente alteritárias? Se por um lado tivemos uma grande manifestação dos estudantes no uso do aplicativo, e a substituição do principal ambiente virtual da disciplina pelo próprio WhatsApp, por outro lado tivemos uma reorganização (por parte dos alunos) do uso dessa ferramenta, e uma utilização nem sempre pautada em interesses ligados à disciplina em si, mas a questões de interesse pessoal, ainda que os estudantes fossem constantemente orientados pelos monitores a reforçar seu acesso ao principal 
ambiente virtual da disciplina, a plataforma Moodle Multimeios.

Diante de tal conflito de ordem didáticometodológica, os monitores da disciplina passaram a responder às dúvidas dos alunos além dos horários estabelecidos no cronograma de atendimento virtual, que inicialmente foi proposto de terças às sextas-feiras, no horário da tarde. Esses horários foram definidos com o objetivo de dar aos estudantes e aos monitores da disciplina a oportunidade de planejaremse para participar dos ambientes virtuais de ensino em horários que lhes fossem mais acessíveis. Porém, mesmo após essa indicação que fizemos, o volume de mensagens no WhatsApp e pedidos de informações feitos fora do horário estabelecido para atendimento virtual continuou a crescer sucessivamente. Mais que isso: mesmo sendo postadas fora do horário estabelecido (e abordando questões que podiam ser solucionadas com o acesso à plataforma Moodle Multimeios), as questões que não eram respondidas de forma imediata pelos monitores, rapidamente se tornavam polêmicas no grupo do WhatsApp, pois os estudantes queriam ter suas dúvidas respondidas imediatamente, no momento em que julgassem oportuno. Assim, analisandose o discurso dos estudantes a partir das postagens que faziam no grupo do WhatsApp, percebíamos um discurso de certa forma autoritário e pouco democrático, centrado unicamente nos interesses de um dos pólos participantes da disciplina, comprovando que todo discurso "procura modificar uma situação" (MAINGUENEAU, 2006, p. 96).

Temos aqui um verdadeiro jogo discursivo: ainda que estivessem reorientando as regras de utilização da ferramenta WhatsApp na disciplina de Informática Educativa (não seguindo os horários de atendimento virtual estabelecidos, e postando dúvidas que poderiam ser solucionadas com o acesso à plataforma Moodle Multimeios), os alunos tinham necessidades próprias que os faziam sentir-se desrespeitados se não tivessem suas dúvidas solucionadas no horário que pudessem acessar o WhatsApp (ainda que esse não fosse o horário estabelecido por professores e monitores para o atendimento virtual através do aplicativo).

Consoante a essa questão, Maingueneau (2014) afirma que os discursos estão sempre em constante movimento de choque, pois sua natureza é essencialmente dialógica. A partir do uso do WhatsApp, podemos, consequentemente, afirmar que tivemos dois discursos em ação na disciplina de Informática Educativa: o discurso oficial (promovido pelo corpo docente) de utilização dos ambientes virtuais e das tecnologias acessadas na disciplina; e o discurso dos próprios estudantes, que se opuseram (direta ou indiretamente) ao discurso oficial de utilização das tecnologias. Assim, na ótica dos estudantes que agiam dessa forma, suas necessidades estavam acima das formalidades da disciplina: se pudessem acessar o WhatsApp só à noite, eles o fariam nesse horário, mesmo que o turno da noite não estivesse reservado para o atendimento virtual dos monitores da disciplina. Mais que isso: ainda que acessassem o aplicativo fora do horário estabelecido para atendimento virtual dos monitores da disciplina, alguns estudantes não se contentavam em aguardar que suas dúvidas fossem atendidas no horário oficial estabelecido, gerando um choque discursivo que fazia com que as dúvidas postadas tivessem de ser quase necessariamente sanadas no tempo dos próprios estudantes.

Essa "distorção" (por parte dos alunos) dos propósitos iniciais do uso do aplicativo na disciplina teve efeitos aparentemente contraditórios: por um lado, essa utilização descentralizada do WhatsApp fez com que os estudantes reorganizassem seus horários de estudo da disciplina usando o aplicativo como ferramenta de enriquecimento no acesso aos conteúdos (textos, dúvidas, informes, etc.). Por outro lado, a utilização descentralizada do WhatsApp também fez com que os estudantes tentassem delimitar o próprio ritmo de andamento das atividades planejadas pelos docentes, exigindo que suas dúvidas fossem sanadas no grupo oficial da disciplina fora do horário oficialmente estabelecido por professores e monitores. Nesse sentido, percebemos uma comunicação que, apesar 
de se dar de forma intensa e fluida através do aplicativo, nem sempre ocorreu de forma alteritária (motivo pelo qual vemos choques comunicativos entre docentes e discentes da disciplina).

\section{CONSIDERAÇÕES FINAIS}

Conforme debatemos ao longo deste ensaio, o uso de tecnologias em contexto educacional não depende apenas do professor, mas igualmente da forma como os alunos utilizam os recursos tecnológicos. Essa utilização tem quase sempre um aspecto democrático, pois incentiva uma descentralização do acesso ao conhecimento, dando ao aluno autonomia para desenvolver estratégias de utilização das tecnologias que auxiliem sua aprendizagem através de uma abordagem dinâmica dos conteúdos.

Se interpretarmos esse fenômeno de um ponto de vista puramente político, ficaremos satisfeitos em saber que o ensino híbrido, aplicado na disciplina de Informática Educativa conseguiu cumprir seu objetivo de estimular o aluno a construir uma rotina de planejamento de estudos, e a incrementar sua própria capacidade comunicativa através da manipulação einterpretação direta dos diversos meios tecnológicos usados na disciplina. Isso foi, sem dúvida, uma experiência proveitosa de compartilhamento de atividades dentro do ambiente presencial de ensino (a universidade) e fora deste ambiente (nos ambientes virtuais trabalhados pelo Laboratório Multimeios da Faculdade de Educação da UFC).

Por outro lado, não podemos negar que o uso do WhatsApp, como rede social de suporte à disciplina ora discutida, abriu questionamentos diversos em relação a como os alunos realmente interpretavam a utilização desse aplicativo, e de que forma esse uso era feito.

O objetivo inicial, de aperfeiçoamento da comunicação mantida com os estudantes matriculados na disciplina, foi plenamente atingido através do WhatsApp. A quantidade de alunos participantes na disciplina Informática Educativa era considerável, e o uso do Facebook na disciplina era feito unicamente de forma pedagógica através do compartilhamento de vídeos elaborados pelos alunos e da aplicação de um fórum de apresentação dos estudantes (sem o uso do Messenger). Isso contribuiu para que adotássemos o WhatsApp como rede social de suporte comunicativo, pois todos os discentes matriculados faziam uso do aplicativo. Todavia, apesar de a ideia inicial ter sido a de utilizar o aplicativo apenas como ferramenta comunicativa, para divulgar informes rápidos sobre a disciplina, o uso que os discentes fizeram do WhatsApp modificou completamente a comunicação mantida entre professores e alunos.

Podemos concluir, então, que o uso do WhatsApp em nossa disciplina ultrapassou completamente qualquer expectativa que estabelecemos para essa ferramenta tecnológica. A rede social mostrou toda sua popularidade entre os estudantes, em grande parte pela praticidade em promover comunicações quase instantâneas entre os participantes do grupo.

Além disso, o fato de estar conectado praticamente $24 \mathrm{~h}$ por dia, fez o WhatsApp ultrapassar o volume de interações do próprio ambiente virtual oficial da disciplina, o Moodle Multimeios. Este fato se comprovou pela quantidade de dúvidas e mensagens que os estudantes postavam no grupo da disciplina no WhatsApp, dúvidas essas que podiam ser rapidamente sanadas com o acesso dos discentes à plataforma Moodle (acesso que era estimulado constantemente pelos monitores de Informática Educativa, mas que foi sendo ignorado pelos discentes).

Finalmente, o uso feito pelos alunos do grupo oficial de WhatsApp também seguiu uma lógica, não apenas descentralizada, mas reorientada pelos objetivos dos próprios estudantes. O fato de os alunos não terem seguido o horário de atendimento virtual de tira-dúvidas, mostra que para eles, suas necessidades pedagógicas eram mais importantes que qualquer diretriz formal da disciplina. Mais ainda: o uso que consideravam que deveriam fazer (e que fizeram) do WhatsApp era absolutamente aceitável em sua ótica, se considerassem que esse uso facilitaria 
o seu acesso aos conteúdos de Informática Educativa.

Nossa experiência pedagógica com o uso do WhatsApp na disciplina de Informática Educativa, na mencionada instituição, foi pedagogicamente muito rica, e nos mostrou facetas que ainda precisam ser refletidas no que tange à utilização de tecnologias na educação. De certa forma, o planejamento da disciplina teve que ser refeito durante o decorrer do próprio semestre letivo, face à popularidade que o aplicativo teve entre os estudantes. Isso fez com que nos conscientizássemos de que na prática, quem iria (re)definir a forma de aplicação do WhatsApp na disciplina seriam os próprios alunos.

A possibilidade de uso do WhatsApp em novas turmas de Informática Educativa no curso de Pedagogia da Universidade Federal do Ceará passou a ser uma realidade pedagógica, em grande parte por conta da experiência realizada no 20 semestre de 2019 . Fica claro, no entanto, que a possibilidade de nova utilização do aplicativo na disciplina exigirá um aperfeiçoamento ainda maior do planejamento pedagógico por parte do corpo docente de Informática Educativa, dando mais ênfase a extrema popularidade que o WhatsApp goza entre o público discente, e acima de tudo ao grande potencial comunicativo que essa ferramenta possui.

Em suma, essa experiência formativa ratificou nossa constatação de que o uso de tecnologias na educação não deve ser promovido de forma mecânica ou rígida, por motivos simples: primeiro, porque isso inviabiliza (ou pelo menos dificulta) o acesso do estudante aos conhecimentos trabalhados na disciplina, e na construção de sua própria aprendizagem. E segundo, por que a depender da própria tecnologia a ser utilizada (em nosso caso, o WhatsApp), os próprios discentes conseguem reorientar a utilização da ferramenta, de forma a buscar a maneira mais prática e descentralizada de usála, fortalecendo, assim, sua própria autonomia estudantil (o que do ponto de vista pedagógico, pode representar um enriquecimento da aprendizagem dos alunos).

\section{REFERÊNCIAS}

ALVES, Paulo. WhatsApp supera Facebook e é o aplicativo mais popular do mundo. Portal Techtudo, São Paulo, 18 de janeiro de 2019. Disponível em https://www.techtudo. com.br/noticias/2019/01/whatsapp-superao-facebook-e-e-o-aplicativo-mais-popular-domundo.ghtml. Acesso em 24 out. 2020

DIESEL, Daniela; MATOS, João Felipe. Espaços educativos inovadores e o olhar dos professores para a ação docente. In: Revista Educação e Cultura Contemporânea, PGE,UNESA, Rio de Janeiro, v. 16, n. 43, abr/jun, 2019.

GALVÃO, Nadielli Maria dos Santos. O Youtube como ferramenta de estudo para o exame de sufi ciência em contabilidade. In: Revista EDaPECI, São Cristóvão-SE, v. 19, n.2, p.76-84, mai/ago, 2019.

KAPLUN, Mario. Uma pedagogia da comunicação. In: APARICl, Roberto: Educomunicação - para além do 2.0. São Paulo: paulinas, 2012.

LOPES, Maria Immacolata Vassalo. Pesquisas de recepção e educação para os meios. In: CITELLI, Adilson. Educomunicação: construindo uma área de conhecimentos. São Paulo: Paulinas, 2011.

MCLUHAN, Marshall. Os meios de comunicação como extensões do homem. São Paulo: Cultrix, 2007.

MAINGUENEAU, Dominique. Gênese dos discursos. São Paulo: Parábola Editorial, 2006.

Dicionário de análise do

discurso. São Paulo: Contexto, 2014.

MARTIN-BARBERO, Jesus. A comunicação na educação. São Paulo: Contexto, 2014.

MORAN, José Manuel. Leituras dos meios de comunicação. São Paulo: Pancast Editora, 2002. 
RODRIGUES, Eric Freitas. Tecnologia, inovação

e ensino de história: o ensino híbrido e suas possibilidades. Orientadora: Profa. Dra. Samantha Viz Quadrat. 98 f. Dissertação de Mestrado Profissional em Ensino de História. Universidade Federal Fluminense - UFF, Instituto de Ciências Humanas e Filosofia. Departamento de História, 2016. Disponível em https://app.uff.br/riuff/ bitstream/1/4604/1/Tecnologia\%2C\%20 Inova\%C3\%A7\%C3\%A30\%20e\%20Ensino\%20 de\%20Hist\%C3\%B3ria\%20o\%20Ensino\%20 H \% C 3 \% A D brido \% 20 e \% 20 suas $\% 20$ possibilidades.pd>.

SILVA, Marco. Sala de aula interativa. São Paulo: edições Loyola, 2014.

SOARES, Ismar. Educomunicação: o conceito, o profissional, a aplicação. São Paulo: Paulinas, 2011.

WAJNSZTEJN, Marina; ANDRÉ, Cláudio Fernando; AZEVEDO, Adriana Barroso de. Blended learning como estratégia de engajamento no ensino superior: relato de uma experiência de aprendizagem conectada, colaborativa e social. In: Revista EDaPECI, São Cristóvão-SE, v.20, n.1, p.22-36, jan/abr 2020. 